\title{
Outcome Feedback Effects on Risk Propensity in an MCPLP Task
}

\author{
Lewis A. Taylor, III \\ University of North Texas \\ Phillip D. Hall \\ St. Ambrose \\ Richard A. Cosier \\ University of Oklahoma \\ Vicki L. Goodwin \\ University of North Texas
}

\begin{abstract}
In this experimental analysis, the effects of outcome feedback on risk propensity were assessed within the multiple-cue-probability-learning-paradigm (MCPLP). The individual decision maker in this task received outcome feedback on a decision-by-decision basis. It was hypothesized that information on his/her success or lack of success (outcome feedback) on each decision would influence the decision to risk (commit) resources. Hierarchical regression results revealed that after all other performance effects had been partialled out, current outcome feedback explained much of the commitment decision.
\end{abstract}

Decision makers have to make decisions which can be characterized by uncertainty, incomplete information, complexity, novelty, iteration, and the use of judgment (e.g., Taylor, 1987). Decision making in uncertain environments, without complete information about relevant variables and the relationships among these variables, has been a topic of research in the study of strategic decision making (Ungson, Braunstein \& Hall, 1981). For some time, the Brunswik (1955) lens model has been promoted for examining this and other related issues (e.g., Cosier, 1978; Taylor, Cosier \& Ganster, 1979). In a laboratory setting (e.g., Cosier, 1978), this perspective has provided insight into decision-making processes and the effects of variables on decision outcomes (Schwenk, 1982).

The Brunswik lens model is a paradigm with broad applications to the study of decision making. Since its introduction nearly forty years ago, the lens model has been the basis for hundreds of scientific studies examining a multitude of decision-making variables. The lens model assumes that there are three basic elements in a decision-making event: a decision maker, information, and a decision criterion.

Direct all correspondence to: Lewis A. Taylor III, University of North Texas, Department of Management, College of Business Administration, Denton, TX 76203. 
As the decision maker uses information to make a judgment, he or she weighs the various pieces of information in terms of relevance to the criterion. The quality of the decision reflects how well the judgmental use of information matches the actual value of information. In other words, the closer the decision maker's policy for utilizing information is to the "objective" relationship of the information to the criterion, the better will be the decision.

Applications of the lens model have frequently incorporated a series of decisions within the multiple-cue-probability-learning-paradigm (MCPLP). The information related to the decision criterion is presented as a set of numeric cues that the decision maker uses to make prediction decisions. Because the information is not perfectly correlated with the criterion, the $M C P L P$ has been suggested as a means to examine decision making under conditions of uncertainty (Cosier, 1983; Mitroff, 1974). Since decision making under uncertainty has long been of interest to strategy researchers, the $M C P L P$ may provide one method of examining strategic decision variables under controlled conditions (Cosier, 1983).

In this research note, a further explication of this $M C P L P$ research stream and a more complete model of the specific decision-making task is presented. The results support the explanatory power of immediate feedback on the commitment decision in a decision task, which may be of interest to researchers desiring to investigate the salient features of decision making in complex tasks under controlled conditions.

\section{Prior Research and Hypothesis}

The data used for the analysis described in this study were obtained using the MCPLP Brunswik lens model perspective (1955). Some of the results were reported in an earlier study (Taylor, 1987).

The results of the two relevant laboratory experiments using the particular task of interest in this paper (Taylor, 1987; Taylor et al., 1992) indicate that there are several effects pertinent to the topic of outcome feedback. In the first experiment (Taylor, 1987), the effects of assigned goal levels (easy, moderate, difficult, and impossible), numbers of suggested alternative strategies (ten, five, and zero), and time (a series of four decision blocks) on both performance in the decision task and the degree of commitment to (acceptance of) the assigned goal level, were tested. Goals and strategies marginally affected performance and goals significantly influenced commitment. More recently, Taylor et al. (1992) reported significant goal effects on decision quality and commitment to goals within a similar study. These studies suggested that easier goals may lead to better performance on a complex task. Also, people may commit quicker to easier goals.

Research using other $M C P L P$ tasks has produced conflicting implications about the effects of outcome feedback. In a comprehensive survey article, Balzer, Doherty and O'Connor (1989) define task information (TI) as including information about the criterion values in an MCPLP setting. Thus, feedback about the actual value of a criterion would reflect TI. Balzer et al. (1989) conclude that it is TI versus cognitive (subjective) information that positively influences performance. In addition, York, Doherty and Kamouri (1987) suggest that outcome feed- 
back may interact with cue reliability to influence judgment. Other studies, however, suggest that decision-making biases (Brehmer, 1980), randomness or "noise" in outcomes (Hammond, Summers \& Deane, 1973), and expertise of the decision maker (Benson \& Onkal, 1992; Fischer, 1982) make outcome feedback unnecessary or harmful for making decisions. Thus, the impact of outcome feedback under conditions of high uncertainty may be negative. Despite predicting different effects, the prior MCPLP research suggests that outcome feedback, at least initially, will have some type of impact on performance.

Using other decision-making paradigms, research results suggest that outcome feedback may require decision aids to help with its interpretation (Kleinmuntz \& Thomas, 1987), it can influence individual decision making differently than group decision making (Tindale, 1989), and it can influence choice of decision style (Wofford \& Goodwin, 1990). Outcome feedback also may interact with goal level to enhance performance (Earley, Northcraft, Lee \& Lituchy, 1990).

Although the aforementioned studies address important issues regarding the impact of outcome feedback on certain aspects of decision making and performance, none is specifically concerned with the influence of outcome feedback on commitment. Some evidence does exist, however, suggesting that luck, ability, effort, and task attributions affect decisions to invest resources following success or failure feedback (Walsh \& Henderson, 1989). Also, specific feedback (Kernan \& Lord, 1989) can affect escalation behavior (i.e., pcople may commit earlier as they become familiar with the results of their decisions)(Bowen, 1987). These results are pertinent to this research because in this study we examined the influence of feedback on risk propensity, our operationalization of commitment to (acceptance of) the goal. This approach to commitment involved investment of resources, and represents an alternative way to define commitment to the typical questionnaire method using verbal statements.

Commitment has been the object of various alternative definitions in the social science literature. Commitment has been operationalized through introspective self-reports (e.g. asking how committed someone is to an assigned goal), the differences between assigned and personal goals, or inferences from performance (e.g. effort shows commitment; Locke \& Latham, 1990). Taylor (1987) criticized these approaches due to: their affective, as opposed to objective measurement; their inability to differentiate between subjects; and their reliance on self reported insights. Instead, Taylor et al. (1992) argue that commitment should include a risk dimension that is measured based on behavior. This reflects the assumption that someone is committed to a course of action when they risk their resources toward attainment of a goal. Outcome feedback is important because it is the evidence upon which a person assesses their chances for future success. If, for example, behavior leads to outcome feedback that reflects success, then a person seems likely to commit to that behavior for future decisions. Conversely, behavior associated with failure should cause a lower likelihood of commitment to the failed course of action.

The individual decision maker in this study received outcome feedback on a decision-by-decision basis. It was hypothesized that information on his/her success or lack of success (outcome feedback) on each decision would influence the 
commitment decision (Hammond, McClelland \& Mumpower, 1980) such that success would be associated with quicker commitment.

\section{Method}

\section{Subjects and Procedures}

A total of 120 male and female undergraduate business students performed an individual financial prediction task force. They participated in sessions with about four other subjects. The all volunteer subjects were seated in front of a set of instructions, response forms, and four stacks of $203 \times 5$ cards. In the instructions, subjects learned that they were to assume the role of a financial analyst. It did not matter what their actual backgrounds were, they needed to use the information presented in this study to make a series of financial predictions. The stacks of 20 cards represented four profit centers in a fictitious electronics company. On side one of each card, three numbers with financial labels (current ratio, inventory turnover, and debt-to-equity ratio) were presented. Participants predicted price earnings $(\mathrm{P} / \mathrm{E})$ ratios using these three cues. These cues ranged from 1 to 20 . Unknown to the subjects, they were actually equally weighted to the criterion (at approximately a .5 correlation) and had near zero intercorrelations among themselves. The challenge for the subjects was to determine the best policy for using the information cues by processing the outcome feedback and making accurate predictions. Outcome feedback was the primary source for improving predictions because after each prediction, subjects turned over the card to side two and viewed the "correct" $\mathrm{P} / \mathrm{E}$ value (outcome feedback). They saw for each prediction if they were correct, or how far off their answer was. As they proceeded through each stack of 20 cards, one card at a time, they attempted to learn how to use the three cues to make better predictions. Outcome feedback provided direct evidence of success or failure and thus reflected on how each subject used the cue information to predict P/E ratios.

Participants were given the option to commit to one of four randomly assigned goals (easy, moderate, difficult, and impossible) in each performance block and earn money as illustrated in Table 1 . Subjects could commit to their goals after any of their 20 predictions for each set of goals. Once they made a commitment, they would receive a payoff if they made their goal according to Table 1 . Commitment could be made in each block and the longer it was delayed, the less the total payoff, but the more some partial payment was protected (e.g., earlier commitments led to larger potential rewards but more risk). Since payoffs were based on reaching assigned goals, this established the salience of the commitment decisions. The task took no longer than 1.75 hours to complete. Subjects were paid $\$ 8.00$ each after the entire study was completed. Up until that time, they were told that pay was dependent upon performance. Regardless of their performance outcomes, the maximum was paid to all participants because of the likelihood that some of the subjects would find it impossible to meet the performance goal.

\section{Task Complexity}

The task used for this study, contrary to simpler situations where subjects can eventually "figure out" with relative ease what is going on if given enough time, 
was uncertain throughout the life of the data collection period. This is because about $25 \%$ of the variance was left unexplained and randomly distributed throughout the task $\left(R^{2} \simeq .75\right)$. The task was complex because it conformed to the typology by Campbell (1988), in which he proposed that the probabilistic nature of information and uncertainty are key features of complex judgment tasks when people assess information and make predictions.

Table 1. Commitment and Reward Schedules

The following reward schedule was used in this study. All subjects were given the same schedule and were free to refer to it at any time. Note that 100 points is equal to $\$ 1.00$.

PROFIT CENTER (A), (B), (C), OR (D)

INITIAI. STAKF $=100$ points for each profit center

\begin{tabular}{ccccc} 
Trial & Wager & Reward & Protect & Total Payoff/Profit Center \\
\hline 1. & 100 & 200 & - & $=200$ \\
2. & 95 & 190 & 05 & $=195$ \\
3. & 90 & 180 & 10 & $=190$ \\
4. & 85 & 170 & 15 & $=185$ \\
5. & 80 & 160 & 20 & $=180$ \\
6. & 75 & 150 & 25 & $=175$ \\
7. & 70 & 140 & 30 & $=170$ \\
8. & 65 & 130 & 35 & $=165$ \\
9. & 60 & 120 & 40 & $=160$ \\
10. & 55 & 110 & 45 & $=155$ \\
11. & 50 & 100 & 50 & $=150$ \\
12. & 45 & 90 & 55 & $=145$ \\
13. & 40 & 80 & 60 & $=140$ \\
14. & 35 & 70 & 65 & $=135$ \\
15. & 30 & 60 & 70 & $=130$ \\
16. & 25 & 50 & 75 & $=125$ \\
17. & 20 & 40 & 80 & $=120$ \\
18. & 15 & 30 & 85 & $=115$ \\
19. & 10 & 20 & 90 & $=110$ \\
20. & 05 & 10 & 95 & $=105$ \\
& - & - & 100 & $=100$ (never commit)
\end{tabular}

Example: Let's say you have made 9 predictions without making a wager and therefore not committing to your goal. You now decide to commit to your goal after decision \#9 and before decision \#10. You are wagering 55 points to gain 110 points if you make your goal; by delaying to trial ten, you have guaranteed 45 points minimum reward. You check the space next to \#10 on your answer sheet (see next page). Then you draw a line through the remaining commitment spaces for that profit center. Only after you have done this can you proceed with making the rest of your predictions in that profit center. This same procedure applies to all profit centers. The example on the next page has two possible results:

(1) If successful in achieving your goal, you would receive $\$ 1.55$ for that profit center.

(2) If unsuccessful in achieving your goal, you would receive 45 cents for that profit center.

(Continued) 
Table 1. Continued

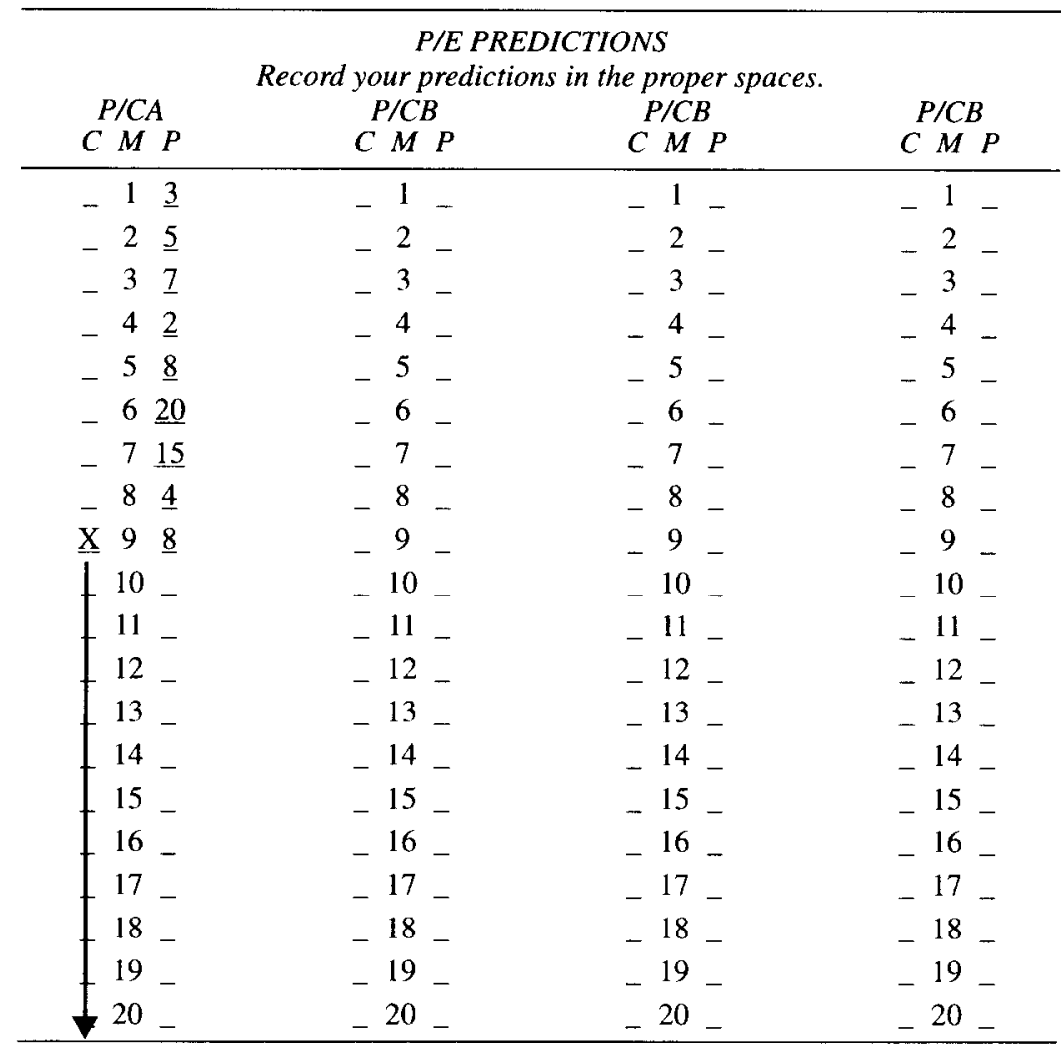

Remember: When you decide to commit, you must mark the space on the left and draw a line through the rest before making a prediction decision for that month in order to validate your earnings. After you commit, complete the predictions in that profit center.

\section{Manipulations}

The design of this study incorporates a between subjects, goal level variable and a within subjects, prediction blocks variable consisting of four blocks of 20 predictions each. The four goal levels reflected various degrees of goal difficulty as determined by prior studies (Taylor, 1987; Taylor et al., 1992). A unit of error was represented by a difference of one integer from the correct answer. Thus, if a subject predicted a P/E ratio of 6 and the correct answer was 4, this decision resulted in 2 units of error. Over a block of 20 predictions, subjects in the easy goal condition had 4 units of error as their goal; the moderate goal subjects had 3 units of error; the difficult goal subjects had 2 units of error; and the impossible goal subjects had 1 unit of error.

\section{Performance Variables}

A decision success variable was calculated for each of the four blocks of 20 decisions. The number of decisions which were within the goal error rate $(4=$ easy; $3=$ moderate; 2 = difficult; $1=$ impossible) were counted up to the time of the deci- 
sion to commit to the goal level. If a subject committed after decision number six in block two, the number of correct decisions up to then was the decision success variable. In this specific task, it was expected that a decision maker would be less willing to commit unless the subject was able to make, and was actually making, successful predictions within the goal error rate. These decision success factors were labeled $D S 1, D S 2, D S 3$, and $D S 4$; one for each block of twenty decisions. The higher the decision success variable in each block, the larger the number of successful decisions up to the point of commitment. This variable assessed current decision success (see Table 2).

Additional decision success variables for each goal level were calculated from blocks 1, 2, and 3 to account for previous decision success. These variables were not calculated for block 4 since this block represented final performance and no subsequent performance was assessed in this experiment. A variable was created that accounted for the total number of successful decisions in the first 3 blocks, regardless of when the subjects committed. The total number of successful decisions for each block was designated COR1, COR2, and COR3 for blocks 1,2, and 3 , respectively. A second, total, cumulative variable was also calculated for all correct decisions over the 3 blocks. They were CUMI (equal to CORI), CUM2 $(C O R 1+C O R 2)$, and $C U M 3(C O R 1+C O R 2+C O R 3)$. These are measurements of total decision success (see Table 2).

In addition, an indication of the average success rate over each block of decisions was added as a dummy variable. Individuals had been instructed regarding

Table 2. Summary of Variables in the Hierarchical Regression Analyses

\begin{tabular}{|c|c|}
\hline Variable & Operationalization \\
\hline Goal level & $\begin{array}{l}\text { Dummy variable reflecting goal level [easy ( }+ \text { or }-4 \text { units of error), } \\
\text { moderate }(+ \text { or }-3 \text { units of error), difficult }(+ \text { or }-2 \text { units of error), } \\
\text { impossible ( }+ \text { or }-1 \text { unit of error)]. }\end{array}$ \\
\hline \multicolumn{2}{|c|}{ Average and Total, Previous Decision Success Variables } \\
\hline COR1, COR $2, C O R 3$ & $\begin{array}{l}\text { Variables reflecting number of previous correct decisions in blocks } 1 \text {, } \\
\text { and } 3 \text {, respectively. }\end{array}$ \\
\hline CUM1, CUM2, CUM3 & $\begin{array}{l}\text { Variables reflecting previous, cumulative correct decisions }(\mathrm{CUM} 1= \\
\mathrm{COR} 1 ; \mathrm{CUM} 2=\mathrm{COR} 1+\mathrm{COR} 2: \mathrm{CUM} 3=\mathrm{COR} 1+\mathrm{COR} 2+\mathrm{COR} 3 \text { ). }\end{array}$ \\
\hline$A V E 1, A V E 2, A V E 3$ & $\begin{array}{l}\text { Dummy variable reflecting whether the assigned goal of achieving a } \\
\text { specific error rate in blocks } 1,2 \text {, and } 3 \text {, respectively, was achieved } \\
\text { [coded as } 1 \text { if within assigned goal (easy, moderate, difficult, } \\
\text { impossible) to achieve a specific error rate; coded as } 0 \text { if not within } \\
\text { assigned goal]. }\end{array}$ \\
\hline
\end{tabular}

Current Decision Success Variable (Outcome Feedback)

$D S 1, D S 2, D S 3, D S 4 \quad$ The number of decisions that were within the assigned goal to achieve a specific error rate in the current block at the time of the decision to commit.

Commitment Variable

COM1, COM2, COM3, The trial number in blocks $1,2,3$, and 4, respectively, when the decision COM4 was made to commit. 
performance, but were not told their average error rates for the blocks, although they could calculate them with the task materials in order to compare performance with goals. Answer sheet and observational evidence revealed that nearly all subjects calculated their average scores for performance as they progressed. This average score variable was scored as 0,1 based on whether the average error rate was within the goal for each block. An average error rate of 2.85 would be within goal level 3 and coded as 1 , whereas an average error rate of 4.25 would not be within goal level 3 and coded as 0 . These variables were designated as $A V E I$, $A V E 2$, and $A V E 3$ for each of the first three blocks, respectively (see Table 2).

\section{Hierarchical Regressions}

Data for 120 subjects were used as input to this analysis. The decision success variables were analyzed in hierarchical multiple regressions in order to examine the variance in the decision to commit to assigned goals in the decision task. Four separate regressions were run with the four decisions to commit to the assigned goal level in a block (20 decisions) as the dependent variables; these were COMI, COM2, COM3, and COM4 (for blocks 1, 2, 3, and 4, respectively; see Table 2). The scores on the commitment variable represented the trial number in each block when the decision was made to commit. Since Taylor (1987) found a goal level effect on the decision to commit, goal level was dummy coded and entered in the first step of the hierarchical regressions in order to control for this effect and to assess the amount of explained variance in the commitment variables attributed to goal level (see Table 2). In the second step, the $A V E$ variable was entered when appropriate ( $A V E I$ was included in the second set of equations, $A V E 2$ in the third set, and $A V E 3$ in the fourth set). This variable accounted for success or failure in achieving the goal level in the previous block of decisions. The previous commitment decision was added to the subsequent hierarchical regression in step three to control for the effect of previous commitment on the current decision to commit; $C O M 1$ became an independent variable in the multiple regression when COM2 was the dependent variable, etc. The previous success variables, $C O R$ and $C U M$, were entered in the next two steps of the hierarchical regressions, respectively, to assess and control for the effect of total previous performance (Cohen \& Cohen, 1983). The $C O R$ variable reflected success in the previous block and the CUM variable reflected cumulative success across all previous blocks. The ultimate objective was to assess the effect of current decision success feedback on the current decision to commit. Therefore, these variables (DS1, DS2, DS3, DS4) were entered in the last step of each of the hierarchical regression analyses, respectively.

\section{Results}

\section{Manipulation Checks}

Of primary interest was whether subjects used outcome feedback. An "objective" way to assess this was by comparing the expected performance from random predictions to the actual performance of the subjects. Compared to the expected average random guessing prediction error of 5 units per block of 20 predictions, the subjects in this study averaged $3.20(t=22.93, d f=119, p<.0005), 2.97(t=28.51$, 
$d f=119, p<.0005), 2.90(t=27.06, d f=119, p<.0005)$, and $2.89(t=27.55, d f=$ $119, p<.0005)$ units of prediction error over blocks one through four, respectively. Moreover, learning as evidenced by improvement occurred over all four blocks ( $F$ $=4.12, p<.01)$. This suggests subjects were affected by outcome feedback.

\section{Hierarchical Regression Analyses}

Correlations between variables are presented in Table 3. Means and standard deviations (in parentheses) are presented on the diagonal.

Hierarchical multiple regression was chosen as the primary analytical technique in this study. Hierarchical regression allows inferences about the incremental contribution of a variable because as Cohen and Cohen (1983, p. 120) note, "Some

Table 3. Correlations, Means, and Standard Deviations for all Variables ${ }^{\mathrm{a}}$

\begin{tabular}{|c|c|c|c|c|c|c|c|c|c|c|c|c|c|}
\hline & $A$ & $B$ & $C$ & $D$ & $E$ & $F$ & $G$ & $H$ & $I$ & $J$ & $K$ & $L$ & $M$ \\
\hline \multicolumn{14}{|c|}{$\begin{array}{ll}\mathrm{A} & 12.2^{\mathrm{b}} \\
& (7.2)\end{array}$} \\
\hline B & \multicolumn{13}{|c|}{$\begin{array}{r}.65 * * 10.6 \\
(7.0)\end{array}$} \\
\hline $\mathrm{C}$ & $.46^{* *}$ & \multicolumn{12}{|c|}{$\begin{array}{r}.58 * * 10.5 \\
(7.7)\end{array}$} \\
\hline D & $.60^{* *}$ & $.71 * *$ & $.70 * *$ & $\begin{array}{l}10.5 \\
(8.1)\end{array}$ & & & & & & & & & \\
\hline $\mathrm{E}$ & $.72 * *$ & $.41^{* *}$ & .14 & $.39 * *$ & \multicolumn{9}{|c|}{$\begin{array}{c}5.3 \\
(4.3)\end{array}$} \\
\hline $\mathrm{F}$ & $.54 * *$ & $.74 * *$ & $.35^{* *}$ & $.48 * *$ & $.63^{* *}$ & \multicolumn{8}{|c|}{$\begin{array}{c}4.9 \\
(3.9)\end{array}$} \\
\hline $\mathrm{G}$ & $.42 * *$ & $.45^{* *}$ & $.76 * *$ & $.51 * *$ & $.39 * *$ & $.53 * *$ & \multicolumn{7}{|c|}{$\begin{array}{c}* 4.6 \\
(4.2)\end{array}$} \\
\hline $\mathrm{H}$ & $.57 * *$ & $.55^{* *}$ & $.48 * *$ & $.81^{* *}$ & $.62 * *$ & $.61 * *$ & $.60 * *$ & $\begin{array}{c}4.6 \\
(4.4)\end{array}$ & & & & & \\
\hline I & $-.33 * *$ & $-.35 * *$ & $-.48 * *$ & $-.40^{* *}$ & $.32^{* * *}$ & .08 & -.08 & -.06 & $\begin{array}{l}10.9 \\
(4.4)\end{array}$ & & & & \\
\hline J & $-.23 *$ & $-.40 * *$ & $-.46 * *$ & $-.41 * *$ & $.23^{*}$ & $.19 *$ & -.01 & -.04 & $.72 * *$ & $\begin{array}{l}11.6 \\
(4.3)\end{array}$ & & & \\
\hline $\mathbf{K}$ & $-.18^{*}$ & $-.30^{* *}$ & $-.50^{* *}$ & $-.40^{* *}$ & $.30 * *$ & .16 & .05 & -.04 & $.77 * *$ & $.80 * *$ & $\begin{array}{l}1.8 \\
4.6)\end{array}$ & & \\
\hline $\mathbf{L}$ & $-.30 * *$ & $-.40 * *$ & $-.51 * *$ & $-.44 * *$ & $.30^{* *}$ & .15 & -.05 & -.06 & $.93 * *$ & $.93 * *$ & $.85^{* *}$ & $\begin{array}{l}22.5 \\
(8.9)\end{array}$ & \\
\hline $\mathbf{M}$ & $-.26 * *$ & $-.38 * *$ & $-.52 * *$ & $-.44 * *$ & $.31 * *$ & .16 & -.01 & -.05 & $.90^{* *}$ & $.91^{* *}$ & $.94 * *$ & $.98 * *$ & $\begin{array}{r}34.3 \\
(12.3) \\
\end{array}$ \\
\hline & $\begin{array}{l}\text { tes: } \mathrm{A}= \\
\text { COR2; } \mathrm{K} \\
\text { Dummy } \\
\text { Means a } \\
<.05 ; * *\end{array}$ & $\begin{array}{l}\text { COM I; } \\
=\text { COR3 } \\
\text { variables } \\
\text { and standa } \\
p<.01\end{array}$ & $\begin{array}{l}\mathrm{B}=\mathrm{COM} \\
3 ; \mathrm{L}=\mathrm{CU} \\
\text { s (Goal le } \\
\text { ard deviat }\end{array}$ & $\begin{array}{l}2 ; \mathrm{C}=\mathrm{CO} \\
\mathrm{JM} 2 ; \mathrm{M}= \\
\text { vel, AVE } \\
\text { tions (in p }\end{array}$ & $\begin{array}{l}\text { OM3; D = } \\
=\text { CUM3 } \\
1 . \text { AVE2, }\end{array}$ & $\begin{array}{l}\text { COM4; } \\
\text { and AVE }\end{array}$ & $\begin{array}{l}E=D S 1 ; \\
E 3 \text { ) are no }\end{array}$ & $\begin{array}{l}F=D \\
\text { ot inc }\end{array}$ & $\begin{array}{l}2 ; G=D \\
\text { ded } \\
\text { diagonal }\end{array}$ & $\mathrm{S} 3 ; \mathrm{H}=$ & $S 4 ; I=C$ & $\mathrm{COR} 1=$ & $\mathrm{JM}$ \\
\hline
\end{tabular}


of the basic principles underlying the hierarchical order for entry are causal priority and the removal of confounding or spurious relationships (emphasis added), research relevance, and structural properties of the research factors being studied." The results of the hierarchical multiple regressions in this study are presented in Table 4. The assigned goal levels had a significant influence on commitment explaining approximately $6 \%$ to $20 \%$ of the variance across the four blocks. The calculations of previous performance do not explain significant amounts of variance in the current commitment decision; that is $A V E, C O R$, and $C U M$ explain little of what happened regarding commitment.

The immediately previous commitment decision did explain a large amount of variance in the next decision. The change in the R-square ranged from .20 to .34 in the last three regression analyses. The calculated current success variable based on predictions that fell within the assigned goal error rate up to the commitment decisions ( $D S I, D S 2, D S 3$, and $D S 4)$ was also significant. This variable explained

Table 4. Results of Multiple Hierarchical Regressions

\begin{tabular}{|c|c|c|c|c|}
\hline REGRESSION & $D E P V A R$ & $I N D E P V A R^{a}$ & Change IN R2 & Change IN $F$ \\
\hline \multirow[t]{3}{*}{1} & COMI & LEVEL & .059 & $2.42^{*}$ \\
\hline & & DS 1 & .638 & $241.73^{* * * *}$ \\
\hline & & TOTAL & .697 & \\
\hline \multirow[t]{6}{*}{2} & COM2 & LEVEL & .137 & $6.13^{* * *}$ \\
\hline & & AVE1 & .002 & .32 \\
\hline & & CUMI $^{\mathrm{b}}$ & .003 & .57 \\
\hline & & COM1 & .340 & $73.37 * * * *$ \\
\hline & & DS2 & .313 & $168.40^{* * * *}$ \\
\hline & & TOTAL & .795 & \\
\hline \multirow[t]{7}{*}{3} & COM3 & LEVEL & .199 & $9.63 * * * *$ \\
\hline & & AVE 2 & .007 & 1.01 \\
\hline & & COR2 & .008 & 1.46 \\
\hline & & CUM2 & .020 & $4.95 * *$ \\
\hline & & COM2 & .206 & $39.90 * * * *$ \\
\hline & & DS3 & .367 & $215.31 * * * *$ \\
\hline & & TOTAL & .807 & \\
\hline \multirow[t]{7}{*}{4} & COM4 & LEVEL & .192 & $9.21 * * * *$ \\
\hline & & AVE3 & .014 & 2.05 \\
\hline & & COR3 & .011 & 2.64 \\
\hline & & CUM3 & .000 & .01 \\
\hline & & COM3 & .312 & $73.69 * * * *$ \\
\hline & & DS4 & .321 & $237.21 * * * *$ \\
\hline & & TOTAL & .850 & \\
\hline
\end{tabular}

Notes: a. The independent variables are listed in each regression analysis in their order of entry. b. $\mathrm{CUMI}=\mathrm{COR} \mathrm{l}$ $* p<.10 ; * * p<.05 ; * * * p<.001 ; * * * * p<.0001$ 
$31-37 \%$ of the variance in the second, third, and fourth blocks and approximately $64 \%$ in the first block. Thus, evidence supports the hypothesis that current success is associated with commitment of resources significantly beyond the variance due to the immediate previous commitment decision.

\section{Discussion}

It is clear from the results in Tablc 4 that the commitment behavior of individuals in this task can be well-explained. Three variables accounted for a very large part of the variance in the dependent variables across the separate hierarchial multiple regressions. Outcome feedback was the focus of this analysis, due to its prominence in decision-making research within the Brunswik, MCPLP tradition. It accounted for a significant and large amount of variance beyond other factors. Furthermore, outcome feedback affected subjects' decisions as evidenced by performance levels and improvements over time. This suggests that subjects' behavior changed over time and was not merely due to inertia from prior decisions.

Outcome feedback can explain a large amount of variance in the dependent variable within a Brunswik lens model task. In an iterative, uncertain, complex prediction task with incomplete information, immediate outcome feedback explains much of what an individual chooses to do with respect to accepting assigned goals. If the goal can be reached as measured by decision success, then commitment is more likely. Commitment will be delayed if the decision maker is not reaching the goal on a decision-by-decision basis, even when cue-criterion relations are randomly distributed within a block of decisions.

The differing goal levels accounted for some variance; apparently easier goals made higher decision accuracy more likely. The individual had the same goal level across blocks, so the ease or difficulty of achieving goals remained constant within the built-in random variance of the lens model. Although results indicated that if the subject committed early or late in one block, this behavior was generally repeated in the next block; when an individual changed the time of commitment, it may have been due to the success at predicting on a decision-by-decision basis in the current block of decisions. This information, current outcome feedback, also explained additional variance in the dependent variables as expected.

The use of hierarchical multiple regression potentially gives a much clearer explication of what happens in studies using tasks similar to Taylor (1987) and Taylor et al. (1992). The impact of current performance emphasizes the effect of outcome feedback in this type of complex task. This effect helps clarify research constructs. This is especially important when using controlled designs investigating decision making purported to have features that are strategic in nature (e.g., Taylor, 1987; Taylor et al., 1992). Future research should examine further how feedback might be manipulated for its effects on other variables in addition to decision quality and commitment. We propose that it may be the amount and complexity of the decision cues that influence the ability to process past and present decision success information.

As always, the question of generalizability, or external validity, must be addressed when a laboratory experiment is performed. If the goal is to use results 
obtained in the lab as a guide for behavior in the organization in a one-to-one manner, then ecological validity is of great importance. When an investigation of relationships that can exist between constructs and, therefore, an attempt to build theory is the goal of the experiment, then the concern for generalizability is not as great (Mook, 1983; Locke, 1990). Many questions related to how people make decisions fall in this category since cognitive processes are involved. Because in this study decision making was the focus, the experimental task had characteristics similar to those found in strategy-making tasks, and the methods used for goal setting and providing feedback were not peculiar to this particular setting, the results should provide some practical implications for managers involved in the strategic process. However, the willingness to commit resources based on decision success may not have had the same potential consequences as the commitment of resources in an actual setting. Therefore, to the degree that the consequences are greater in other settings, the results obtained in this experiment may indicate less conservative commitment behavior on the part of the decision makers.

Implications for managers are that, along with benefits of having easier goals for decision makers dealing with complex tasks, decision makers seem to place heavy reliance on perceptions of current (or short term) success when deciding to commit resources. This implies a somewhat short term, narrow focus employed by decision makers faced with uncertainty. Managers may need specific decision aids aimed at presenting more comprehensive, longer term perspectives to improve decisions. It can also be expected that managers faced with recent failures to reach goals, may be reluctant to commit resources because they believe that future improvements are not possible. This pessimism may lead to less risk and poorer long term performance if commitment to reaching goals is related to higher levels of effort as suggested by the goal setting literature (Locke \& Latham, 1990).

\section{References}

Balzer, W.K., Doherty, M.E. \& O'Connor, R. Jr. (1989). Effects of cognitive feedback on performance. Psychological Bulletin, 106: 410-433.

Benson, P.G. \& Onkal, D. (1997). The effects of feedhack and training on the performance of prohability forecasters. International Journal of Forecasting, 8: 559-573.

Bowen, M.G. (1987). The escalation phenomenon reconsidered: Decision dilemmas or decision errors? Academy of Management Review, 12: 52-66.

Brehmer, B. (1980). In one word: Not from experience. Acta Psychologica, 45: 223-241

Brunswik, E. (1955). Representative design and probabilistic theory in a functional design. Psychological Review, 62: $193-217$.

Campbell, D.J. (1988). Task complexity: A review and analysis. Academy of Management Review, 13: 40-52.

Cohen, J. \& Cohen, P. (1983). Applied multiple regression/correlation analysis for the behavior sciences, 2 nd ed. New Jersey: Erlbaum.

Cosier, R.A. (1978). The effects of three potential aids for making strategic decisions on prediction accuracy. Organizational Behavior and Human Performance, 22: 295-306.

Cosier, R.A. (1983). Approaches for experimental examination of the dialectic. Strategic Management Journal, 4: $79-84$.

Earley, P.C., Northcraft, G.B., Lee, C. \& Lituchy, T.R. (1990). Impact of process and outcome feedback on the relation of goal setting to task performance. Academy of Management Journal, 33: 87-105.

Fischer, G.W. (1982). Scoring-rule feedback and the overconfidence syndrome in subjective and probability forecasting. Organizational Behavior and Human Performance, 29: 352-369.

Hammond, K.R., McClelland, G.H. \& Mumpower, J. (1980). Human judgment and decision making. New York: Praeger. 
Hammond, K.R., Summers, D.A. \& Deane, D.H. (1973). Negative effects of outcome feedback in multiple-cue probability learning. Organizational Behavior and Human Performance, 9: 30-34.

Kernan, M.C. \& Lord, R.G. (1989). The effects of explicit goals and specific feedback on escalation processes. Journal of Applied Social Psychology, 19: 1125-1143.

Kleinmuntz, D.N. \& Thomas, J.B. (1987). The value of action and inference in dynamic decision making. Organizational Rehavior and Human Decision. Processes, 39: 341-364.

Locke, E.A. (1990). Generalizing from laboratory to field settings. Lexington, MA: Lexington Books.

Locke, E.A. \& Latham, G.P. (1990). A theory of goal setting and task Performance. Englewood Cliffs: PrenticeHall.

Mitroff, I.I. (1974). A Brunswik lens model of dialectic inquiring systems. Theory and decision, 5: 45-67.

Mook, D.G. (1983). In defense of external invalidity. American Psychologist, 38: 379-387.

Schwenk, C.R. (1982). Why sacrifice rigor for relevance? A proposal for combining laboratory and field research in strategic management. Strategic Management Journal, 3: 213-225.

Taylor, L.A. III. (1987). Decision quality and commitment within a probabilistic environment. Organizational behavior and human decision processes, 39: 203-227.

Taylor, L.A. III., Cosier, R.A. \& Ganster, D.C. (1992). The positive effects of easy goals on decision quality and risk propensity in an MCPLP task. Decision Sciences, 23: 880-898.

Tindale, R.S. (1989). Group versus individual information processing: The effects of outcome feedback on decision making. Organizational Behavior and Human Decision Processes, 44: 454-473.

Ungson, G.R., Braunstein, D.N. \& Hall, P.D. (1981). Managerial information processing: A research review. Administrative Science Quarterly. 26: 116-134.

Walsh, J.P. \& Henderson, C.M. (1989). An attributional analysis of decisions about making commitments. Journal of Social Psychology: 129: 533-549.

Wofford, J.C. \& Goodwin, V.L. (1990). Effects of feedback on cognitive processing and choice of decision style. Journal of Applied Psychology, 75: 603-612.

York, K.M., Doherty, M.E. \& Kamouri, J. (1987). The influence of cue unreliability on judgment in a multiple cue probability learning task. Organizational Behavior and Human Decision Processes, 39: 303-317. 